\title{
POR QUE KANT ESCREVE DUAS INTRODUÇÕES PARA A CRÍTICA DA FACULDADE DO JUÍZO?
}

\author{
Adriano Perin ${ }^{1}$ \\ adrianoperin@yahoo.com.br
}

RESUMO $A$ busca de uma função sistemática para a Crítica da faculdade do juízo frente à autossuficiência dos domínios teórico e prático da razão, que é o resultado que a filosofia crítica kantiana alcança no final da década de 1780 na argumentação da segunda Crítica, suscita a necessidade de um empreendimento que possa garantir a "conexão" (Verknüpfung) ou o "meio de ligação" (Verbindungsmittel) desses domínios. Vale dizer que as duas primeiras criticas garantem a natureza e a liberdade como duas legalidades determinantes apenas no âmbito inerente aos seus domínios próprios. Assim sendo, a terceira Crítica atesta agora um "grande abismo" entre o domínio teórico e o domínio prático da razão. No presente trabalho objetiva-se reconstruir a argumentação das duas introduções da Crítica da faculdade do juízo sustentando que a percepção da necessidade de um novo texto para a introdução da obra está intrinsecamente ligada ao peso sistemático da abordagem do problema da possibilidade de uma passagem (Übergang) entre o domínio teórico da legalidade da natureza e o domínio prático da legalidade da liberdade.

Palavras-Chave Domínios teórico e prático, Natureza, Liberdade, Passagem, Faculdade do juízo

ABSTRACT In face of the self-sufficiency of the theoretical and practical domains of reason, which is the outcome reached by the critical 
philosophy at the end of the 1780s in the second Critique's argumentation, the search for a systematic function for the Critique of the Power of Judgment calls for an enterprise accomplishing the connection (Verknüpfung) or the means for combining (Verbindungsmittel) these domains. Nature and freedom are guaranteed by the first two critiques as determining legalities only within their own domains. The third Critique is therefore able to attest to a "great gulf" between the theoretical and practical domains of reason. By reconstructing the argumentation of both introductions to the Critique of the Power of Judgment, the paper defends that the systemic weight given to the consideration of the problem of the possibility of a transition (Übergang) between the theoretical and the practical domains is the main reason behind the necessity of a new text for the introduction to the work.

Keywords Theoretical and Practical Domains, Nature, Freedom, Transition, Power of Judgment

\section{Introdução}

Diferentemente do texto da introdução da Crítica da razão pura da primeira edição de 1781, que fora conhecido juntamente com a publicação da obra, o manuscrito intitulado Erste Einleitung in die Kritik der Urteilskraft, que Kant teria primeiramente redigido para apresentar a proposta da Crítica da faculdade do juízo, tem seu conteúdo revelado apenas posteriormente à obra e como uma publicação autônoma.

Das palavras de Kant, tanto ao editor da terceira Crítica quanto ao seu aluno Jacob Sigismund Beck que publicaria o manuscrito independentemente, sabe-se que o motivo da substituição do texto não fora outro que o fato de que ele "talvez ainda devesse ser resumid[o]" (Br, AA 11: 122) e que, então, fora "descartado porque era muito longo" (Br, AA 11: 441).

A descoberta de um novo tipo de princípio a priori no sistema das faculdades de conhecimento é datada do ano de 1787 (Cf. Br, AA 10: 514) e, com isso, para o ano de 1788 já é referida uma primeira proposta de publicação da terceira Crítica (Br, AA 10: 532). É, contudo, só em janeiro de 1790 que Kant remete ao editor parte do texto da obra e comunica que a introdução, que já estaria pronta e deveria apenas ser reduzida, e a parte restante seriam enviadas em 15 dias (Br, AA 11: 125). A parte restante do texto seria de fato enviada em fevereiro e no início de março, mas a introdução e o prefácio apenas no final do mês de março (Br, AA 11: 132, 143, 145). 
Ora, diante da constante pressão do editor da Crítica da faculdade do juizo para o envio do manuscrito completo, apresenta-se como um fato curioso que Kant tenha não apenas relegado a reelaboração ou redução do texto da introdução para o último momento, mas propriamente considerado a necessidade da redação de um novo texto.

No presente trabalho, toma-se por tarefa não a consideração ou comparação histórica e filológica dos textos do manuscrito da introdução publicado separadamente e do texto que Kant enviara ao editor como responsável pela apresentação da proposta da obra. De modo diferente, privilegia-se uma consideração sistemática da argumentação de Kant nos mesmos textos com o objetivo de defender a tese de que a redação de um novo texto está essencialmente ligada à mudança de concepção acerca de um problema que suporta o peso da Crítica da faculdade do juízo como um todo, a saber, a passagem entre os domínios teórico e prático da razão. Essa tese é amparada em dois momentos da argumentação do trabalho. A primeira parte enfatiza uma diferença sistemática importante no tratamento da passagem na argumentação da Primeira Introdução em relação à argumentação da Segunda Introdução. A segunda parte especifica a proposta acerca do problema da passagem que é admitida como criticamente adequada para o todo da argumentação da Crítica da faculdade do juízo.

\section{A diferença das propostas das introduções para o problema da pas- sagem entre o domínio teórico e o domínio prático da razão}

Kant aborda o problema da passagem entre o domínio teórico e o domínio prático da razão em dois trechos da argumentação da Primeira Introdução e em três trechos da argumentação da Segunda Introdução, sendo o último destes toda a nona seção e última seção do texto.

Nessa parte do trabalho será defendido que, no que concerne à abordagem da passagem entre o domínio teórico e o domínio prático, é necessário considerar uma notável diferença entre a argumentação das duas introduções, de modo que apenas a Segunda Introdução contempla a proposta crítica assegurada pela argumentação da terceira Crítica no seu todo.

Já pode ser dito que essa diferença consiste no fato de que, ao passo que a argumentação da Primeira Introdução sustenta que a faculdade do juízo de fato estabelece ou deve estabelecer uma passagem entre os domínios teórico e prático e, assim também, proporciona um vínculo entre eles, a argumentação da Segunda Introdução garante que a faculdade do juízo assegura não a passagem em si, mas sim a possibilidade da mesma. 
A consideração dessa diferença na argumentação das duas Introduções é imprescindível para que se entenda que a terceira Crítica nem desconsidera a já garantida autossuficiência dos domínios teórico e prático da razão e nem objetiva empreender uma unidade entre eles de cunho metafísico ou transcendente que, enquanto tal, teria que ser situada além dos limites da filosofia crítico-transcendental kantiana. ${ }^{2}$

$\mathrm{Na}$ Primeira Introdução o papel da faculdade do juízo frente à relação dos domínios teórico e prático da razão é apresentado em dois trechos da seção intitulada "Introdução Enciclopédica da Crítica do Juízo no Sistema da Crítica da Razão Pura”. Nessa seção a argumentação de Kant dá indícios para o leitor se questionar se a mesma considera a função da faculdade do juízo como compreendida entre os domínios da natureza e da liberdade enquanto criticamente garantidos pelas duas primeiras Críticas ou entre esses domínios enquanto duas partes constituintes de um sistema doutrinal da filosofia. ${ }^{3}$ Esse "questionamento" é suscitado principalmente pela abordagem

2 É a tese seminal de Kant na Crítica da razão prática que o uso prático pode ser justificado criticamente e, assim, dotado de um domínio legítimo da razão, apenas na medida em que ele empreende por si só tal justificativa, sem contar constitutivamente com nenhum elemento de cunho teórico. Quer dizer: "[...] a razão prática obtém agora por si mesma, e sem ter acertado um compromisso com a razão [teórica] especulativa, realidade [Realität] para um objeto supra-sensível da categoria de causalidade, a saber, da liberdade (embora, como conceito prático também só para o uso prático), portanto confirma [bestätigt] mediante um factum o que lá meramente poderia ser pensado" (KpV, A 11). Essa tese tem como seu resultado sistemático que o domínio teórico da legalidade da natureza e o domínio prático da legalidade da liberdade são domínios fundamentados de modo autossuficiente.

3 É uma tarefa difícil precisar qual a intenção de Kant nessa seção da Primeira Introdução, de modo que também poderia ser tomado como uma hipótese que a argumentação da mesma não tenha em vista apenas os propósitos a serem considerados no corpo da Crítica da faculdade do juízo. Essa hipótese poderia ser amparada por trechos encontrados nas correspondências de Kant concomitantes ao período de redação da terceira Crítica, nos quais ele afirma também estar trabalhando num sistema da metafísica. Essa intenção pode ser conferida nas seguintes correspondências de Kant:

i. Carta a Marcus Herz de maio de 1789. Br, AA 11: 49. "Eu [...] nos meus 66 anos de idade ainda estou sobrecarregado com o extensivo trabalho de terminar meu plano (parcialmente em produzir a última parte da Crítica, a saber, aquela do Juízo, a qual deve aparecer logo, e parcialmente estruturando um sistema da metafísica, da natureza e também da liberdade, em conformidade com aquelas necessidades críticas)";

ii. Carta a Abraham Gotthelf Kästener de 5 de agosto de 1790. Br, AA 11: 186. Nesta correspondência, escrita poucos dias depois da publicação da terceira Crítica para a feira de Leipzig no final de abril de 1790, Kant diz que "[a]o mesmo tempo permita-me explicar os meus esforços em relação ao criticismo, os quais eu tenho realizado até então não no intuito de (conforme eles poderiam parecer) atacar a filosofia leibniz-wolffiana (eu até a encontro negligenciada em tempos recentes). Meu objetivo é, todavia, seguir a mesma trilha de acordo com um procedimento rigoroso e, por meio dele, alcançar o mesmo objetivo, mas com uma diferença que, ao que me parece, aqueles excelentes homens parecem ter considerado supérflua: a união da filosofia teórica e da filosofia prática. Esta intenção minha será clara quando eu, se viver suficientemente, completar a reconstrução da metafísica num sistema coerente".

Conforme esses trechos indicam, no período da redação da terceira Crítica e mesmo imediatamente procedente à publicação desta, Kant parecia estar trabalhando também num projeto de cunho doutrinal que deveria suceder a filosofia crítico-transcendental e também ser empreendido de acordo com as exigências desta. Contudo, dada a ausência de outras fontes e também o fato de não ser encontrado posteriormente nenhum texto que justifique esse empreendimento de um sistema da metafísica no seu todo, é possível aqui considerar apenas como uma hipótese que a argumentação de Kant no texto da 
que Kant desenvolve dos termos "introdução propedêutica" e "introdução enciclopédica".

Kant concebe uma "introdução propedêutica" como uma "introdução a uma doutrina que se tem em vista" e, por conseguinte, de modo que "precede a doutrina", e uma "introdução enciclopédica" como uma introdução "da própria doutrina em um sistema, ao qual ela pertence como parte" de modo que ela "deveria constituir somente sua conclusão, para indicar seu lugar no conjunto das doutrinas com as quais ela está em conexão por princípios comuns, segundo proposições fundamentais". ${ }^{4}$

A partir do que é garantido nesses trechos pode ser dito que uma "introdução propedêutica" seria uma introdução cujo empreendimento estaria assegurado pela filosofia crítico-transcendental, ao passo que uma "introdução enciclopédica" exigiria que o domínio dos conceitos da natureza e o domínio do conceito de liberdade fossem compreendidos como dois domínios de um sistema doutrinal da filosofia para os quais a faculdade do juízo deveria desempenhar uma função consequente de conexão dos mesmos em um único sistema filosófico.

Num primeiro trecho, onde se refere ao problema da relação do domínio teórico dos conceitos da natureza e o domínio prático do conceito de liberdade, Kant se vale da especificidade da faculdade do juízo de não requerer nenhum domínio constitutivo para justificar a possibilidade de um empreendimento que unificasse a "introdução propedêutica" à "introdução enciclopédica". Assim, ele afirma que

[c]omo aquela faculdade cujo princípio próprio deve ser aqui procurado e colocado (o Juízo) é de espécie tão particular que por si só não produz nenhum conhecimento (nem teórico nem prático) e, apesar de seu princípio a priori, não fornece nenhuma parte à filosofia transcendental, como doutrina objetiva, mas somente o vínculo [Verband] de duas outras faculdades superiores de conhecimento (o entendimento e a razão): pode ser-me permitido, na determinação do princípio de tal faculdade, que não é susceptível de nenhuma doutrina mas meramente de uma crítica, afastarme da ordem, de resto necessária por toda parte, e antecipar uma curta introdução enciclopédica da mesma, e aliás, não no sistema das ciências da razão pura, mas meramente na crítica de todas as faculdades da mente determináveis a priori, na medida em que, entre si, constituem um sistema na mente, e, desse modo, unificar a introdução propedêutica com a enciclopédica. ${ }^{5}$

Primeira Introdução tenha em vista também um empreendimento consequente à terceira Crítica e de caráter doutrinal.

4 Todos os trechos citados em EEKU, 53. AA 20: 241.

5 EEKU, 54. AA 20: 242. 
A argumentação desse trecho garante essencialmente que a faculdade do juízo, sem prescindir do contexto sistemático no qual não possui nenhum domínio constitutivo, fornece o vínculo daquelas faculdades que são compreendidas como legislantes em dois domínios constitutivos, a saber, o entendimento e a razão. É nessa tarefa que Kant encontra a unificação da "introdução propedêutica", que visa manter o juízo como uma faculdade sistematicamente concebida sem um domínio de objetos, com a "introdução enciclopédica", que visa garantir que mediante essa faculdade é assegurado o vínculo daqueles dois domínios constitutivos para os quais o entendimento e a razão são duas faculdades legislantes a priori. Em uma palavra, Kant teria que justificar como a faculdade do juízo empreende a unidade entre os domínios teórico e prático sem que essa faculdade, por si mesma, ocupe um domínio constitutivo da razão.

A realização desse empreendimento consistiria, sem sombra de dúvida, na garantia tanto de que os domínios teórico e prático são dois domínios autossuficientes da razão, como também de que eles são domínios de "uma única e mesma razão pura". Contudo, na consideração da argumentação do trecho citado, restaria saber se esse empreendimento é legítimo e, assim, se ele pode ser sistematicamente concebido nos limites da filosofia críticotranscendental kantiana.

Para que seja possível precisar uma resposta a essa questão, vale considerar ainda um segundo trecho onde Kant apresenta uma referência direta ao conceito da passagem. Neste trecho, por sua vez, Kant argumenta que

[...] revela-se [entdeckt sich] um sistema das faculdades do ânimo [System der Gemütskräfte], em sua relação com a natureza e a liberdade, das quais cada uma tem seus próprios princípios determinantes a priori e, por isso, constituem as duas partes da filosofia (a teórica e a prática) como um sistema doutrinal, e ao mesmo tempo uma passagem [Übergang] por intermédio do Juízo, que através de um princípio próprio conecta [verknüpft] ambas as partes, a saber, do substrato sensivel da primeira filosofia ao inteligível da segunda, pela crítica de uma faculdade (o Juízo), que serve apenas para a conexão [Verknüpfen] e, por si, não pode, decerto, proporcionar nenhum conhecimento. ${ }^{6}$

O que nesse trecho suscita consideração é o fato de Kant agora se referir explicitamente ao domínio dos conceitos da natureza e ao domínio do conceito liberdade enquanto constituintes das "duas partes da filosofia (a teórica e a por "poderes da mente"; "Übergang" por "transição" e "verknüpft/Verknüpfen” por "vincula/vinculação". 
prática) como um sistema doutrinal" e à faculdade do juízo como fornecendo uma passagem entre elas. Não obstante a possibilidade de se conjecturar que Kant concebe essa referência às duas partes da filosofia num sistema doutrinal apenas a partir da garantia fornecida pelas duas primeiras Críticas para este sistema e não propriamente mediante o seu estabelecimento, ou seja, a partir da garantia dos domínios dos conceitos de natureza e do conceito de liberdade como legitimando a divisão da filosofia em teórica e prática, é notável que, por sua vez, o empreendimento de uma passagem entre esses dois domínios da filosofia mediante a faculdade do juízo exigiria de fato que se fosse além dos próprios limites da filosofia crítico-transcendental. Ou seja, essa passagem exigiria uma "introdução enciclopédica" da faculdade do juízo que, agora sim, estabeleceria a necessidade de que essas duas partes da filosofia fossem compreendidas como partes de um sistema doutrinal e no qual a mesma faculdade do juízo desempenharia uma função consequente de conexão das mesmas.

Para resumir, o problema pode ser apresentado do seguinte modo: ou Kant considera os limites da filosofia crítico-transcendental, segundo os quais a faculdade do juízo não pode ser dotada de nenhuma argumentação que não tenha origem nela mesma e, assim, que não é válida além do seu âmbito regulativo, ou ele admite que a mesma faculdade garante a passagem ou o vínculo entre as duas partes da filosofia (a teórica e a prática), isso contudo não mais num empreendimento crítico.

Esse impasse parece ter sido o principal motivo para que Kant considerasse necessária uma nova redação da Introdução à Crítica da faculdade do juízo. Que essa "Crítica" deve ser sistematicamente compreendida nos limites da filosofia crítico-transcendental no seu todo Kant não se cansa de frisar em vários trechos da sua argumentação. É assim que, por exemplo, no texto da Segunda Introdução, encontra-se a garantia de que

[a] crítica [...] não possui no fundo qualquer domínio relativamente a objetos. A razão é que ela não é uma doutrina, mas somente tem que investigar se e como é possível uma doutrina, em função da condição das nossas faculdades e através delas. O seu campo estende-se a todas as pretensões daquelas para colocá-las nos limites da sua correta medida. ${ }^{7}$

Caberia agora considerar, na medida em que se admite que a terceira Crítica empreende uma argumentação que é assegurada pelos limites da filosofia crítico-transcendental, justificar como Kant concebe o problema da passagem 
no contexto da Segunda Introdução, a qual objetiva essencialmente garantir uma apresentação da proposta crítica conferida no todo do corpo da obra.

Porém, antes de ter em atenção especificamente a proposta crítica a ser assegurada pela terceira Crítica no seu todo, será pertinente ainda fazer menção a um trecho da Primeira Introdução, que parece propriamente ser o agente originário do caráter crítico e sistemático da argumentação da Segunda Introdução acerca do problema da passagem.

Assim, já na seção da Primeira Introdução que foi referida há pouco e na qual Kant apresenta a distinção entre uma "introdução propedêutica" e uma "introdução enciclopédica" e também defende a possibilidade de uma justificação da faculdade do juízo mediante a unificação de ambas, encontrase a seguinte referência à especificidade de uma "introdução propedêutica":

As introduções propedêuticas são as habituais, que preparam para uma doutrina a ser exposta, na medida em que apresentam os conhecimentos prévios necessários para isso, a partir de outras doutrinas ou ciências já existentes, para tornar possível a passagem [Übergang]. ${ }^{8}$

Conforme garantido nesse trecho, uma "introdução propedêutica" pretende apenas “tornar possível a passagem”. Esse ponto é fundamental para que se entenda que Kant concebe, na argumentação da Segunda Introdução e também na argumentação da Crítica no seu todo, a justificação da faculdade do juízo apenas e fundamentalmente como uma "introdução propedêutica" a um sistema doutrinal da filosofia e, assim, não ainda como parte do mesmo.

\section{A proposta sistemática da argumentação da Crítica da faculdade do} juízo acerca da passagem entre o domínio teórico e o domínio prático da razão

Em todos os momentos da Segunda Introdução, nos quais Kant considera o problema da passagem, ele sempre diz que a tarefa crítica da faculdade do juízo consiste não no empreendimento da mesma passagem, como admitido na Primeira Introdução, mas sim na garantia da sua possibilidade. A esse respeito vale mencionar os seguintes trechos:

i. "[...] o conceito de liberdade deve tornar efetivo no mundo sensível o fim colocado por suas leis e a natureza em consequência tem que ser pensada de tal modo que a conformidade a leis da sua forma concorde pelo menos com a possibilidade dos fins que nela atuam segundo leis da liberdade"; 9 
ii. “[...] pelo menos provisoriamente, é de supor que a faculdade do juízo [...] produza do mesmo modo uma passagem da faculdade de conhecimento pura, isto é, do domínio dos conceitos de natureza, para o domínio do conceito de liberdade, quando no uso lógico torna possível a passagem do entendimento para a razão"; 10

iii. "[a] faculdade do juízo [...], sem tomar em consideração o elemento prático, dá o conceito mediador entre os conceitos de natureza e o conceito de liberdade que torna possível, no conceito de uma conformidade a fins da natureza, a passagem da razão pura teórica para a razão pura prática". ${ }^{11}$

É digno de nota que no primeiro trecho encontra-se uma das poucas alterações que o próprio Kant viu como necessária para a segunda edição da Crítica da faculdade do juízo de 1793. Assim, ao passo que na primeira edição de 1790 era afirmado que "o conceito de liberdade torna efetivo no mundo sensível o fim colocado por suas leis", na segunda edição é garantido que "o conceito de liberdade deve tornar efetivo no mundo sensível o fim colocado por suas leis". Ora, se de acordo com o trecho da edição de 1790 poderia ser interpretado que a Crítica teria de fato que mostrar como o fim de acordo com o conceito de liberdade é efetivo no mundo sensível que é determinado pela legalidade da natureza, na edição de 1793 Kant precisa sua posição crítica ao assegurar que essa tarefa não é empreendida, mas garantida como possível. ${ }^{12}$

No segundo trecho, por sua vez, é necessário destacar que o fato de que a faculdade do juízo produza uma passagem entre o domínio dos conceitos de natureza e o domínio do conceito de liberdade é tomado por Kant apenas como uma "suposição provisória", sendo que com relação às faculdades que legislam nesses dois domínios, a saber, o entendimento e a razão, é garantido apenas que a faculdade do juízo "torna possível a passagem”. Essa garantia é também conferida no último trecho, onde Kant, assim como nos dois primeiros, assegura que a faculdade do juízo mediante o seu princípio próprio, ou seja, a conformidade a fins da natureza, "torna possível [...] a passagem da razão pura teórica à razão pura prática”.

Ora, essa proposta sistemática da argumentação da terceira Crítica acerca do conceito da passagem entre o domínio teórico e o domínio prático, que é peculiarmente apresentada na Segunda Introdução, tem como um elemento

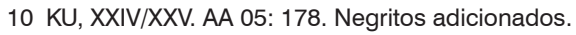

$11 \mathrm{KU}, \mathrm{LV}$. AA 05: 196. Negritos adicionados.

12 Na segunda edição de 1793, lê-se: "[...] der Freiheitsbegriff soll den durch seine Gesetze aufgegebenen Zweck in der Sinnenwelt wirklich machen". O modal "sollen" não aparecia na primeira edição e foi acrescido por Kant no texto da segunda edição. 
imprescindível a autossuficiência desses dois domínios. Kant justifica essa autossuficiência assegurando que

[...] o fato de estes dois diferentes domínios - que, de fato, não na sua legislação, porém nos seus efeitos, se limitam permanentemente ao mundo sensível - não constituírem um só tem origem em que na verdade o conceito de natureza representa os seus objetos na intuição, mas não como coisas em si mesmas, mas na qualidade de simples fenômenos; em contrapartida, o conceito de liberdade representa no seu objeto uma coisa em si mesma, mas não na intuição. ${ }^{13}$

Com isso, considera-se que ambos os domínios da razão quanto às suas legislações, a saber, no domínio teórico a legalidade da natureza e no domínio prático a legalidade da liberdade, não se limitam ao mundo sensível ou à experiência possível. Resta saber, porém, se ambas essas legislações garantem os seus efeitos no mundo sensível.

Quanto ao domínio teórico, a proposta da primeira Crítica assegura que é não só uma possibilidade, mas mesmo uma necessidade que todos os eventos no mundo sensível sejam concebidos como determinados pela legalidade da natureza. No domínio prático, por sua vez, considera-se uma peculiar dificuldade, em parte motivada pelo fato de que todos os eventos no mundo sensível não podem ser prescindidos da sua determinação mediante a legalidade da natureza e em parte motivada pela necessidade de que a liberdade seja sistematicamente concebida como uma legalidade de caráter inteligível.

Pode ser dito que a mesma dificuldade não encontra (e sistematicamente não pode encontrar) uma resposta na Crítica da razão prática pelo motivo de que ela exige a consideração de ambos os domínios da razão. ${ }^{14}$ Isso se deve ao

$13 \mathrm{KU}, \mathrm{XVIII.} \mathrm{AA} \mathrm{05:} 176$.

14 Com isso deve-se considerar que, na argumentação da Crítica da razão prática, as consequências do estabelecimento ou da efetivação prática da liberdade precisam ser tomadas como constitutivamente válidas unicamente no domínio do uso prático da razão. Ora, se a liberdade deve ser estabelecida unicamente no domínio prático, e se as consequências constitutivas desse estabelecimento não podem ser consideradas como válidas fora do mesmo, isso não significa que no domínio teórico a razão não possa "tomar por certo" que tal estabelecimento tenha sido edificado no domínio prático. Pelo contrário, pode-se sim dizer que a efetividade da liberdade no domínio prático apresenta resultados sistemáticos que são "notados" ou assumidos pela razão no domínio teórico, embora nunca dotados de valor constitutivo para este domínio. Mas, não obstante o estabelecimento prático da liberdade e o reconhecimento sistemático do mesmo, é importante ter presente que há um problema que não pode ser abordado a partir do mesmo estabelecimento apenas e para o qual não poderia, então, ser dada uma resposta na Crítica da razão prática. Esse problema constitui a admissibilidade da liberdade como uma causalidade atuante no mundo sensível, determinado pela causalidade da natureza. Eis a apresentação do problema nas palavras da última seção da Analítica da segunda Crítica: "[...] está ainda pendente uma outra dificuldade acerca da liberdade, na medida em que ela deve unir-se ao mecanismo natural em um ente que pertence ao mundo sensível [Sinnenwelt]; uma dificuldade que, mesmo depois de tudo o que foi concedido até aqui, ameaça a liberdade de completo naufrágio" (KpV, A 179). E, também, a impossibilidade de responder o mesmo: "Dir-se-á que a resolução da dificuldade aqui exposta encerra muitos obstáculos internos e que não é 
fato de ela exigir que se considere não apenas que uma legalidade inteligível (a liberdade) torne possível os seus efeitos no mundo sensível, o qual é determinado pela legalidade da natureza, mas também que esta legalidade da natureza seja pensada de tal modo a garantir um efeito daquela.

A partir dessa "exigência", é de se desconfiar que essa seria uma tarefa para a Crítica da faculdade do juízo. De fato, Kant assegura que a consideração da natureza como conforme a fins mediante a faculdade do juízo permite que também um fim segundo a legalidade da liberdade seja possível no mundo sensível. Assim, a passagem é especificada na terceira Crítica não como empreendida entre os próprios domínios teórico e prático e as suas legalidades determinantes, mas garantida como possível na medida em que os efeitos dessas legalidades não são contraditórios no mundo sensível. $\mathrm{Ou}$ seja, a passagem é compreendida no sentido de uma consideração conforme a fins da legalidade da natureza que permite a admissibilidade de um fim da legalidade da liberdade no mundo sensível.

Kant garante essa maneira em que a possibilidade da passagem é pensada:

[...] se bem que os fundamentos de determinação da causalidade segundo o conceito de liberdade (e da regra prática que ele envolve) não se possam testemunhar na natureza e o sensível não possa determinar o supra-sensível no sujeito, todavia é possível o inverso (não de fato no que respeita ao conhecimento da natureza, mas sim às consequências do primeiro [conceito de liberdade] sobre a segunda [natureza]). ${ }^{15}$

E ele ainda explicita a mesma passagem na descrição do fim de acordo com o conceito de liberdade:

[o] efeito segundo o conceito de liberdade é o fim terminal [Endzweck]; o qual (ou a sua manifestação no mundo sensível [Sinnenwelt]) deve existir para o que se pressupõe a condição da possibilidade do mesmo na natureza (do sujeito como ser

sequer susceptível de uma apresentação clara. Mas por acaso alguma outra, que se tentou ou possa tentar, é mais fácil e compreensível? Antes, poder-se-ia dizer que os mestres dogmáticos da Metafísica teriam provado mais a sua astúcia do que a sua fraqueza no fato de terem afastado tanto quanto possível da vista este ponto difícil, na esperança de que, se não falassem dele, tampouco alguém facilmente pensaria nele. Se se deve auxiliar uma ciência, então todas as dificuldades têm de ser descobertas e têm de ser procuradas, até aquelas que tão secretamente ainda a estorvam [...]. Contrariamente, se as dificuldades forem intencionalmente ocultadas ou afastadas por meios paliativos, elas cedo ou tarde irrompem em males incuráveis que levam a ciência à ruína de um completo ceticismo" (KpV, A 185). É, de fato, impressionante o caráter negativo com o qual Kant encerra a Analítica da segunda Crítica no que concerne a esse problema da compatibilidade da causalidade da natureza e da liberdade no mundo sensível. Esse "caráter negativo", contudo, parece estar sistematicamente justificado na impossibilidade de se apresentar uma solução para um problema que compromete a relação de ambos os usos da razão, e que, então, não pode ser tomado como resolvido a partir de um deles apenas, dado suas legalidades terem força constitutiva apenas no âmbito intrínseco aos seus domínios.

15 KU, LV. AA 05: 195. 
sensível, isto é, como ser humano). A faculdade do juízo que pressupõe a priori essa condição, sem tomar em consideração o elemento prático, dá o conceito mediador entre os conceitos de natureza e o conceito de liberdade que torna possível, no conceito de uma conformidade a fins da natureza, a passagem da razão pura teórica à razão pura prática, isto é, da conformidade a leis segundo a primeira para o fim terminal segundo aquele último conceito. Na verdade desse modo é conhecida a possibilidade do fim terminal, que apenas na natureza e com a concordância das suas leis se pode tornar efetivo. ${ }^{16}$

\section{Conforme esses trechos deixam claro, a proposta da terceira Crítica} acerca do problema da passagem releva a necessidade sistemática de que "os fundamentos de determinação" da legalidade da natureza e da legalidade da liberdade sejam mantidos como autossuficientes. Todavia, o que pode ser sim garantido como possível é que a natureza seja considerada de tal modo que as "consequências" do conceito de liberdade, ou, mais precisamente, o fim colocado por suas leis, seja concorde com a sua legislação teórica.

A consideração da natureza, de modo a garantir a possibilidade de um fim segundo o conceito de liberdade, não pode ser tomada como uma consideração

16 KU, LV. AA 05: 196. Rohden e Marques traduzem "Sinnenwelt" por "mundo dos sentidos". Vale dizer que o conceito do fim terminal ("Endzweck"), enquanto efeito do conceito de liberdade no mundo sensível, é concebido por Kant na Segunda Introdução e na argumentação da terceira Crítica como um conceito que leva em conta as possibilidades sistemáticas disponíveis à faculdade do juízo na consideração do problema da passagem. Assim sendo, pode ser também assegurado que esse conceito, enquanto um fim da legalidade da liberdade para o qual o juízo garante a possibilidade na consideração conforme a fins da legalidade da natureza, é uma figura pensada por Kant como concorde com os limites da filosofia crítico-transcendental, segundo os quais a argumentação da terceira Crítica pode garantir apenas a possibilidade da passagem e, também, somente no sentido de que as legalidades da natureza e da liberdade são concebidas de tal modo que os seus efeitos são compatíveis no mundo sensível. Na argumentação precedente à terceira Crítica, Kant parece ter feito apenas duas referências breves a esse conceito de "Endzweck", sendo ambas encontradas na primeira Crítica. Assim, em 1781, no texto do Cânone, Kant afirma que "[...] os fins essenciais são ou o fim terminal [Endzweck] ou os fins subalternos que como meios pertencem necessariamente àquele. Este último não é outro senão o inteiro destino [ganze Bestimmung] do homem, e a filosofia a respeito deste último chama-se Moral" (KrV, A 840/B 868). Rohden e Moosburger traduzem "Endzweck" por "fim último" e "ganze Bestimmung" por "inteira destinação". Também em 1787, no texto dos Paralogismos, Kant argumenta que "[s] gegundo a analogia da natureza dos seres vivos neste mundo, com respeito aos quais a razão tem que necessariamente admitir como princípio que nenhum órgão, nenhum poder, nenhum impulso, portanto, nada do que pode encontrar-se neles é supérfluo ou desproporcionado ao seu uso, portanto, nada que não seja conforme a fins [nichts... mithin Unzweckmäßiges anzutreffen], mas que tudo é proporcionado exatamente ao seu destino [seiner Bestimmung] na vida - o homem, que unicamente pode conter o último fim terminal [letzten Endzweck] de tudo isso, teria de ser a única criatura a fazer exceção a tudo isso" (KrV, B 425). Rohden e Moosburger traduzem "nichts... mithin Unzweckmäßiges" por "não conforme a um fim", "seiner Bestimmung" por "sua destinação" e "letzten Endzweck" por "objetivo final”. Não obstante esses trechos poderem ser tomados como gênese da abordagem da Doutrina do Método da Crítica da Faculdade do Juízo Teleológica acerca do conceito de fim terminal, é proeminente ter presente que Kant apenas apresenta esse conceito, enquanto um fim possível da liberdade no mundo sensível, na argumentação própria da terceira Crítica. Eis porque, se tomadas em comparação as duas tabelas que são apresentadas no final das introduções contendo um esquema sistemático das faculdades do entendimento, do juízo e da razão, confere-se que o conceito de "fim terminal" é apresentado como um princípio a priori da faculdade da razão apenas na Segunda Introdução. 
em sentido constitutivo, eis porque o seu lugar sistemático é apenas concedido num momento da filosofia crítico-transcendental que não é situado nem no âmbito interno da argumentação constitutiva do domínio teórico e do domínio prático e nem no âmbito transcendente de um novo domínio constitutivo da razão. ${ }^{17}$ Esse é também o motivo de a passagem ser especificada não entre as legalidades teórica e prática em si mesmas, que imprescindivelmente devem ser mantidas como autossuficientes, mas entre uma consideração regulativa da primeira que permite um fim mediante a segunda e, justamente por isso, ser garantida apenas como possível.

17 É pertinente aqui apresentar uma divergência com LEBRUN, 1993, p. 69-92. Esse autor, ao defender que na terceira Crítica é encontrada uma passagem dos domínios da natureza ao domínio da liberdade, compreende que a mesma passagem se configura "[...] do julgamento teleológico à teologia moral" ( $p$. 70). Assim, ele considera que "[...] Kant promete a seu leitor conduzi-lo da 'legalidade' da natureza ao 'fim terminal da razão prática' - e [que] a Crítica descreve escrupulosamente essa curva" (p. 89), sendo que "[...] o estudo do juízo reflexionante, demonstrando isso, libera-nos do ponto de vista teórico e dispõenos, portanto, a reconsiderar a obra crítica" (p. 91). O mesmo autor conclui que "[f]azendo desembocar a Crítica do Juízo em uma teologia 'desconhecida até então', Kant parece fazer, com singular pré-ciência, o traçado topográfico da 'verdadeira teodicéia' hegeliana" (p. 92). Não obstante muitos trechos da Doutrina do Método da Faculdade do Juízo Teleológica à primeira vista parecerem favorecer uma leitura como essa, é imprescindível que se entenda que essa posição não pode ser considerada como a posição kantiana na Crítica da faculdade do juízo. Assim, deve-se ter presente que Kant assegura na Observação que procede aos parágrafos 87-88 que discutem a "prova moral da existência de Deus" que "[e]ssa prova moral não é por assim dizer um argumento inventado de novo, mas quando muito é somente uma nova discussão do mesmo" (KU, 438. AA 05: 458). Essa afirmação pareceria suficiente para que o leitor pudesse desconfiar que a posição de Kant é concorde tanto com a posição da primeira Crítica de que no domínio teórico não há nenhum lugar para uma tal prova bem como com a argumentação da segunda Crítica de que ela pode ser considerada no domínio prático, mas apenas num momento sistematicamente admitido como consequente à própria fundamentação do mesmo. $\mathrm{E}$, de fato, ao se considerar os referidos parágrafos, pode-se conferir que Kant argumenta que "[e]ste argumento moral não deve fornecer qualquer demonstração objetivamente válida da existência de Deus, nem demonstrar ao cético que existe um Deus, mas sim que, se ele quiser pensar consequentemente de um ponto de vista prático, terá que aceitar este princípio entre as máximas da sua razão prática" (Nota em KU, 425. AA 05: 450/451. Negrito adicionado). Se a passagem, no sentido em que é admitida por Lebrun, "[...] pressupõe um conceito liberdade e da natureza (da qual só se pode pensar um autor externo) que teria que conter uma compreensão [Einsicht] do substrato supra-sensível da natureza e da unicidade desta com aquilo, que torna possível mediante a liberdade no mundo", isso não significa, de modo algum, que a terceira Crítica empreenda tal passagem e, assim, que legitime tal pressuposição, que teria que ser compreendida também em sentido teórico (Trecho citado em nota de KU, 423. AA 05: 449). Kant precisamente enfatiza que "[...] a questão de saber se não se pode demonstrar que a realidade objetiva do conceito de um fim terminal da criação é também suficiente para as exigências de tipo teórica da razão pura [...] é o mínimo que se pode exigir à filosofia [teórica] especulativa que se empenha em ligar o fim moral com os fins da natureza, através da ideia de um único fim; mas mesmo este pouco é bem mais do que ela pode realizar" (KU, 431. AA 05: 454). Ao se conjecturar que a passagem entre os domínios teórico e prático é empreendida mediante uma argumentação de caráter teológico na terceira Crítica, talvez seja necessário não esquecer as palavras com as quais Kant conclui a mesma obra: "[...] a consideração dos fins da natureza - dos quais apresenta uma rica matéria - [possibilita] a ideia de um fim terminal que a natureza não pode apresentar; por conseguinte pode fazer sentir a necessidade de uma teologia que determine suficientemente o conceito de Deus para o uso prático supremo da razão, mas não pode produzi-la e fundá-la suficientemente com base nas suas provas" (KU, 482. AA 05: 484. Negritos adicionados). 
Essa consideração é realizada mediante o princípio de conformidade a fins da natureza que, na medida em que é "objetivamente contingente" segundo a determinação teórica da legalidade da natureza e "subjetivamente necessário" para a faculdade do juízo mesma, ${ }^{18}$ assegura também a garantia da possibilidade de um fim segundo o conceito de liberdade no mundo sensível. Segundo Kant, “[...] a possibilidade disso não é descortinável, mas a objeção segundo a qual aí se encontra uma pretensa contradição pode ser suficientemente refutada". ${ }^{19}$ Isso significa que a proposta da terceira Crítica não compreende nem uma prova de que a legalidade da liberdade é uma causalidade determinante no mundo sensível nem de que neste é de fato demonstrado um efeito da mesma, mas sim que é garantido que um tal efeito não é contraditório com a determinação da legalidade teórica da natureza enquanto compreendida como conformidade a fins.

Poderiam agora ser considerados os diversos momentos nos quais Kant se refere à passagem no contexto dos problemas tratados no corpo do texto da Crítica da faculdade do juizo. ${ }^{20}$ Contudo, a garantia de que a passagem

18 Conforme formulação do texto da Primeira Introdução: "[...] uma legalidade, objetivamente contingente, mas subjetivamente (para nossa faculdade de conhecimento) necessária, isto é, uma conformidade a fins da natureza, e aliás a priori" (EEKU, 54/55. AA 20: 243). Na Segunda Introdução Kant também assegura que "[a] concebida concordância da natureza na multiplicidade das suas leis particulares com a nossa faculdade de encontrar para ela a universalidade dos princípios tem que ser ajuizada segundo toda a nossa compreensão [Einsicht] como contingente, mas igualmente como imprescindível para as nossas necessidades intelectuais, por conseguinte como conformidade a fins, pela qual a natureza concorda com a nossa intenção, mas somente enquanto orientada para o conhecimento" (KU, XXXVIII. AA 05: 187). Rohden e Marques traduzem "Einsicht" por "perspiciência". A conformidade a fins da natureza é "objetivamente contingente" porque no domínio teórico da razão este princípio não pode ser concebido como dotado de validade constitutiva. Agora, que ela seja "subjetivamente necessária" se deve não a uma justificação constitutiva empreendida pela faculdade do juízo reflexionante, mas sim à "força constitutiva" da tarefa que lhe é imposta, a saber, a consideração da natureza como conforme a fins.

19 KU LIV/LV. AA 05: 195.

20 Esses momentos compreendem principalmente o § 59 da Crítica da Faculdade do Juízo Estética, intitulado "Da beleza como símbolo da moralidade", e os §§ 83-88 da Crítica da Faculdade do Juízo Teleológica. Os mesmos têm sido motivo de debate na literatura que considera a argumentação da terceira Crítica como empreendendo de fato uma passagem entre os domínios teórico e prático da razão. Assim, vale considerar, por exemplo, a discussão recente entre ALLISON, 2001, p. 195-218; e GUYER. In: SEDGWICK, p. 19-53. Num capítulo do seu trabalho intitulado "Juízo reflexionante e a passagem da natureza a liberdade", Allison defende que o problema da passagem é "um problema essencialmente prático... ao invés de um problema sistemático" (p. 204) e que uma resposta ao mesmo é encontrada na Crítica da Faculdade do Juízo Estética pelo fato de ser empreendida, mediante o juízo de gosto, a partir da promoção e do aprimoramento da receptividade da mente para o sentimento moral. Assim, embora fazendo menção à argumentação da Crítica da Faculdade do Juízo Teleológica acerca do "fim terminal", a solução apresentada por Allison figura essencialmente na Crítica da Faculdade do Juízo Estética. Guyer, por sua vez, embora concorde que o "imenso abismo entre a natureza e a liberdade... pode e deve ser superado mediante o uso prático da liberdade" (p. 33) ou "apenas de um ponto de vista prático" (p. 21), argumenta que é "a crítica do juízo teleológico [que] deve superar a lacuna entre a natureza e a liberdade" (p. 35). Tendo presente a argumentação apresentada neste capítulo acerca do problema da passagem na terceira Crítica, podem ser considerados os seguintes pontos diante das posições defendidas por esses dois autores: 
entre os domínios teórico e prático é justificada apenas como possível e especificada de modo tal a manter a sua autossuficiência é suficiente para que se compreenda que, em todos esses momentos, a proposta sistemática da obra é totalmente assegurada pelos limites da filosofia crítico-transcendental.

Ora, a preocupação de encontrar na terceira Crítica uma unidade entre os domínios teórico e prático da razão, que seria estabelecida pela passagem entre os mesmos mediante a faculdade do juízo reflexionante, poderia levar o leitor a passar com olhos apressados os trechos com os quais Kant inicia os dois momentos mais importantes da sua argumentação acerca da mesma passagem na Segunda Introdução. É assim que, na segunda seção, ele precisamente afirma que "[...] na verdade subsist[e] um abismo intransponível entre o domínio do conceito da natureza, enquanto sensível, e o do conceito de liberdade, como suprassensível". ${ }^{21}$ E ainda, na nona seção, considera que

[o] entendimento é legislador a priori em relação à natureza, enquanto objeto dos sentidos, para um conhecimento teórico da mesma numa experiência possível. A razão é legisladora a priori em relação à liberdade e à causalidade que é própria desta (como aquilo que é supra-sensível no sujeito) para um conhecimento incondicionado prático. O domínio do conceito de natureza, sob a primeira e o domínio do conceito de liberdade, sob a segunda legislação, estão completamente separados através do grande abismo que separa o supra-sensível dos fenômenos, apesar de toda a influência recíproca que cada um deles por si (cada um segundo as respectivas leis fundamentais) poderia ter sobre o outro. $\mathrm{O}$ conceito de liberdade nada determina no

i. A proposta da terceira Crítica não objetiva um empreendimento da passagem, mas a garantia da possibilidade da mesma;

ii. O problema da passagem, embora intrinsecamente conectado à necessidade prática da admissibilidade de um fim da liberdade no mundo sensível, não é um problema unicamente prático pelo fato de que ele exige a consideração de ambos os domínios da razão. Assim sendo, o problema da passagem é essencialmente um problema sistemático. Eis porque Kant concebe a sua abordagem apenas no contexto da faculdade do juízo reflexionante e, neste contexto, garante uma resposta ao mesmo que releva tanto a argumentação das duas primeiras Críticas como as possibilidades sistemáticas disponíveis à faculdade do juízo;

iii. Se fosse abordada a proposta da terceira Crítica acerca da possibilidade da passagem, que é especificada no sentido de que uma consideração conforme a fins da natureza legitima a possibilidade de um fim da liberdade no mundo sensível, seria necessário atender tanto ao contexto da faculdade do juízo estética quanto ao contexto da faculdade do juízo teleológica. Isso porque é na primeira que se encontra a justificação própria da faculdade do juízo reflexionante, que mediante o princípio de conformidade a fins da natureza assegura a mesma possibilidade, e é na segunda que se encontra a justificação da admissibilidade do fim terminal, enquanto efeito possível da liberdade no mundo sensível. Eis porque, na nona seção da Segunda Introdução, Kant faz menção a ambos esses contextos. Assim, ele afirma tanto que "[a] espontaneidade no jogo das faculdades de conhecimento, cujo acordo contém o fundamento $\mathrm{d}[\mathrm{o}$ ] prazer, torna o conceito pensado [a conformidade a fins da natureza] adequado para uma mediação da conexão dos domínios do conceito de natureza com o conceito de liberdade nas suas consequências", como que "[...] a faculdade do juízo [...] torna possível, no conceito de uma conformidade a fins da natureza, a passagem da razão pura teórica para a razão pura prática, isto é, da conformidade a leis segundo a primeira para o fim terminal segundo aquele último conceito" (Respectivamente KU, LVII e LV. AA 05: 197 e 196. Negrito acionado no primeiro trecho e o segundo trecho já foi citado anteriormente).

$21 \mathrm{KU}, \mathrm{XIX}$. AA 05: 176. Negrito adicionado. 
respeitante ao conhecimento teórico da natureza; precisamente do mesmo modo o conceito de natureza nada determina às leis práticas da liberdade. Desse modo não é possível lançar uma ponte de um domínio para o outro. ${ }^{22}$

Tendo presente o caráter do problema expresso nestes trechos pode ser dito que é extremamente importante que se considere que na argumentação da Crítica da faculdade do juízo, e agora no sistema crítico transcendental como um todo, "subsist[e] um abismo intransponível" entre o domínio teórico e o domínio prático da razão e que, pelo motivo de esse "grande abismo" sistematicamente manter esses domínios como "completamente separados", "não é possível lançar uma ponte" entre eles. ${ }^{23}$

Todavia, isso não significa que Kant esquece na terceira Crítica que é "uma única e mesma razão" que opera de modo autossuficiente nos domínios teórico e prático. Pelo contrário, nessa obra ele agora deixa claro qual o sentido crítico em que a mesma unidade deve ser considerada no sistema crítico-transcendental como um todo. Ou seja,

[...] a faculdade do juízo [...] dá a si própria a lei com respeito aos objetos de uma satisfação [Wohlgefallens] tão pura, assim como a razão faz com respeito à faculdade de apetição; e ela vê-se referida, quer devido a esta possibilidade interna no sujeito, quer devido à possibilidade externa de uma natureza concordante com ela, a algo no próprio sujeito e fora dele que não é natureza e tampouco liberdade, mas que, contudo, está conectado com o fundamento desta, ou seja, o supra-sensível no qual a faculdade teórica está ligada, em vista da unidade, com a faculdade prática de um modo comum e desconhecido. ${ }^{24}$

22 KU, LIII/LIV. AA: 05: 195. Negritos adicionados.

23 A esse respeito, confere-se DÜSING, 1990. Nesse artigo, ao considerar o problema da unidade da razão a partir da passagem entre a legalidade da natureza e a legalidade da liberdade na terceira Crítica e, como consequência, a partir da "mediação" dessas legalidades, Düsing afirma que "[...] tal unidade poderia ser concebida, se ainda, apenas metafisicamente, como foi buscada nas várias metafísicas idealistas da arte, iniciadas por Schiller e desenvolvida por Schelling e por Hegel. Pelo contrário, Kant entende aquela mediação apenas como uma passagem. Ela não supera [ou torna inválida, 'overcome'] a autossuficiência dos princípios da razão teórica e prática junto com seus domínios separados da natureza e da liberdade, mas contudo os mantém na sua validade original e autônoma" (p. 79). No mesmo contexto também pode ser lida a seção "Caracterização da problemática da passagem da natureza à liberdade" (p. 102-115) do livro desse autor: DÜSING, Klaus, 1968 (Kantstudien Ergängzungshefte, v. 96).

$24 \mathrm{KU}, 258 / 259$. AA 05: 354. Rohden e Marques traduzem "Wohlgefallen" por "complacência". Vale notar que nesse trecho Kant considera as faculdades teórica e prática, que asseguram a fundamentação crítica para os dois domínios da razão, nos mesmos termos que na Crítica da razão pura fora considerada, no âmbito inerente ao domínio teórico, a relação do entendimento e da sensibilidade. Assim, num trecho do final da Introdução da primeira Crítica, lê-se que "[...] há dois troncos do conhecimento humano que talvez brotem de uma raiz comum, mas desconhecida a nós, a saber, sensibilidade e entendimento: pela primeira objetos são-nos dados, mas pela segunda são pensados" (KrV, A 15/B 29). Um comentário desse trecho que concorda com a posição defendida neste trabalho pode ser encontrado em HENRICH, 1994, p. 19. Nesse trabalho Henrich garante que "[c]ertamente, poderia ser o caso que a sentença em questão revela o caráter preliminar do sistema da Crítica, então encorajando os sucessores de Kant a penetrar os seus princípios mais profundamente. Assim é que Reinhold, Fichte, Hegel e Cohen a interpretaram, e Heidegger a toma desse modo também. Mas poderia ser o caso de que o 'desconhecido para nós' é abordado a partir da certeza da compreensão de que a tarefa de revelar a raiz comum situa-se fora dos 
Que mediante a faculdade do juízo seja realizada uma consideração conforme a fins da natureza e que essa consideração esteja conectada com o "suprassensível" ou, conforme também dito por Kant, "garanta a possibilidade da sua determinação", não significa, de modo algum, que a mesma faculdade empreenda tal determinação ou, antes disso, que ela sistematicamente tenha legitimidade para fazê-lo. Se esse "supra-sensível" foi mantido como indeterminado para o domínio teórico e foi concebido como determinado no domínio prático com sentido e validade apenas prática, agora a faculdade do juízo pode sistematicamente considerar o mesmo na relação desses domínios apenas de um modo regulativo e segundo um princípio legítimo somente para ela mesma.

Portanto, a faculdade do juízo reflexionante pode garantir uma consideração tal da natureza que permite a possibilidade de um fim de acordo com a legalidade da liberdade no mundo sensível, mas a unidade dos domínios teórico e prático nos quais essas legalidades operam de modo constitutivo deve essencialmente ser mantida, enquanto tal, "de um modo comum e desconhecido". O que quer dizer que a mesma unidade só poderia ser estabelecida além do âmbito que a filosofia crítico-transcendental garante como único possível para a consideração da razão no todo dos seus empreendimentos. Isso a preço de desmedir tanto a meticulosa organização dos diversos momentos dessa filosofia, bem como os limites impostos pela mesma enquanto condições últimas de legitimidade da própria razão. A redação de um novo texto para a apresentação da proposta da Crítica da faculdade do juizo tem em conta precisamente a indisposição do próprio Kant de pagar tal preço.

\section{Conclusão}

Este trabalho procurou defender que o problema da possibilidade de uma passagem entre os domínios teórico e prático da filosofia kantiana é o responsável pela redação de um segundo tex to como propício para apresentação da proposta sistemática da Crítica da faculdade do juízo. Para tal, sustentouse que a compreensão dessa tarefa sistemática encarregada à faculdade do juízo reflexionante, a qual não pudera ser tratada apenas no âmbito de um dos domínios da razão precisamente porque exige a consideração da relação de ambos, depende fundamentalmente da necessidade de que se entenda a 
argumentação da terceira Crítica como assegurada pelos limites da filosofia crítico-transcendental num todo.

Com isso, considerou-se que a abordagem do mesmo problema na introdução publicada com a obra contempla tanto à imprescindível necessidade de que seja mantida a autossuficiência dos domínios teórico e prático, quanto à impossibilidade de se desconsiderarem os limites garantidos como condições de legitimidade da própria razão, resultados estes que a filosofia crítica alcança nas duas primeiras Críticas. Num primeiro momento foi possível ponderar que entre as duas introduções há uma diferença sistemática em relação ao peso que Kant fornece à faculdade do juízo diante do problema da passagem entre o domínio teórico e o domínio prático. Enquanto que no texto da Primeira Introdução confere-se que a faculdade do juízo de fato estabelece ou deve estabelecer uma passagem entre os dois domínios da razão e, assim também, proporciona um vínculo entre eles, na argumentação da Segunda Introdução é sustentado que a faculdade do juízo assegura não a passagem em si, mas sim a possibilidade da mesma. Num segundo momento, por fim, objetivou-se apresentar a proposta sistemática da argumentação da Crítica da faculdade do juízo acerca da passagem. Argumentou-se que a especificidade dessa proposta configura não o empreendimento de uma passagem entre os próprios domínios teórico e prático e as suas legalidades determinantes, mas a garantia da sua possibilidade na medida em que os efeitos dessas legalidades não são contraditórios no mundo sensível.

\section{Referências}

\section{Obras de Kant}

. Kritik der reinen Vernunft. (KrV). Hrsg. von Raymund Schmidt. Hamburg: Felix Meiner, 1993. (Philos. Bibliothek Bd. 37 a). Tradução da edição A de Manuela Pinto dos Santos e Alexandre Fradique Morujão. Lisboa: Calouste Gulbenkian, 1997. Tradução da edição B de Valério Rohden e Udo Baldur Moosburger. São Paulo: Abril Cultural, 1991.

. Kritik der praktischen Vernunft. $(\mathrm{KpV})$. Hrsg. von Karl Vorländer. Hamburg: Felix Meiner, 1993. (Philos. Bibliothek Bd. 38 a). Tradução de Valério Rohden. São Paulo: Martins Fontes, 2002.

- Erste Einleitung in die Kritik de Urteilskraft. (EEKU). In: Akademie Textausgabe, Bd. IX, Berlin: de Gruyter, 1968; Anmerkungen, Berlin/New York: de Gruyter, 1977. Tradução de Rubens Rodrigues Torres Filho. In: Duas introduções à Crítica do juizo. São Paulo: Iluminuras, 1995. 
Kritik der Urteilskraft. (KU). Hrsg. von Karl Vorländer. Hamburg: Felix Meiner, 1993. (Philos. Bibliothek Bd. 39 a). Tradução de Valério Rohden e Antonio Marques. Rio de Janeiro: Forense Universitária, 1995.

. Briefwechsel. (Br). In: Kants gesammelte Schriften. Hrsg. von der Deuschen Akademie der Wissenschaften, Bde. X-XIII. Berlin und Leipzig: de Gruyter, 1928. Tradução de Arnulf Zweig. New York: Cambridge University Press, 1999.

\section{Literatura}

ALLISON, Henry E. Kant's theory of taste: a rereading of the Critique of aesthetic judgment. New York: Cambridge University Press, 2001.

DÜSING, Klaus. Die Teleologie in Kants Weltbegriff. Bonn: H. Bouvier u. Co. Verlag, 1968. (Kantstudien Ergängzungshefte, v. 96).

DÜSING, Klaus. Beauty as the transition from nature to freedom in Kant's Critique of judgment. Noûs, n. 24, p. 79-92, 1990.

GUYER, Paul. The unity of nature and freedom: Kant's conception of the system of philosophy. In: SEDGWICK, Sally (Ed.). The reception of Kant's critical philosophy. Cambridge: Cambridge University Press, 2000. p. 19-53.

HENRICH, Dieter. On the unity of subjectivity. In: HENRICH, Dieter. The unity of reason: essays on Kant's philosophy. Trad. Richard Velkley. London: Harvard University Press, 1994.

LEBRUN, Gerard. A terceira Crítica ou a teologia reencontrada. In: LEBRUN, Gerard. Sobre Kant. São Paulo: Iluminuras: Edusp, 1993. p. 69-92. 